\title{
Design of On-line Monitoring System of Transmission Line Based on Beidou Short Message
}

\author{
Gui'liang Deng ${ }^{1, *}$, Jing Luo $^{2}$, and Baolin Gui ${ }^{3}$ \\ ${ }^{1}$ Changsha University of Science and Technology \\ ${ }^{2}$ State Key Laboratory of Disaster Prevention \& Reduction for Power Grid Transmission and Distribution Equipment \\ ${ }^{3}$ YongZhou Power Supply Company, Hunan Electric Power Co. Ltd
}

\begin{abstract}
In view of the problem that the lack of wireless mobile network in remote mountainous areas makes the transmission line online monitoring data transmission difficult, this paper proposes a data transmission scheme using Beidou short message communication. And aiming at the problems of small data transmission and low reliability in Beidou short message communication, a new data coding method is designed. The actual results show that: the proposed transmission line online monitoring system based on Beidou short message communication has a high success rate of transmission line information collection, which is an efficient and reliable scheme for transmission line online monitoring in remote mountainous areas.
\end{abstract}

\section{Introduction}

On-line monitoring of transmission line condition is an important means to ensure the safety of long-distance transmission line. The establishment of data transmission mode with good real-time performance and high reliability is an important research direction for the design of transmission line status on-line monitoring system. At present, optical fiber communication, GPRS, power line carrier and other communication technologies are generally adopted in the power system ${ }^{[1-3]}$. However, the wireless network signal in remote mountainous areas is poor and the cost of laying wired network is high, so the above communication technologies cannot meet the demand. In recent years, in view of the above problems, studies have found that it is a feasible scheme to take Beidou short message communication technology as a transmission mode with its features of large existing range, no blind area, safety and reliability ${ }^{[4-5]}$. In addition, the transmission mode is improved. Data splitting transmission ${ }^{[6-7]}$, compression transmission ${ }^{[8]}$ and data merging transmission are used to improve the transmission efficiency. However, the risk information of transmission lines is characterized by large amount of data and various types of data, and the above methods cannot meet the requirements.

Aiming at the above problems, this paper developed an online risk monitoring system for transmission lines based on Beidou short message communication: The risk information of the transmission line is collected by the sensor, and the data is packaged and processed by the embedded chip and sent to the control center through the Beidou communication module. On this basis, combined with the characteristics of large amount and variety of data transmitted by the system, a byte space allocation strategy is designed to improve the transmission efficiency of Beidou short message communication.

\section{The overall design of the system}

\section{1. System architecture}

As shown in Fig. 1, the transmission line monitoring system based on Beidou short message communication mainly consists of four parts: data acquisition module, data processing control module, Beidou short message module and control center.

The data acquisition module includes a temperature sensor, a humidity sensor, a wind speed sensor, a wind direction sensor, an atmospheric pressure sensor, a precipitation sensor, a visibility sensor, a light intensity sensor, a ultraviolet sensor and a dust concentration sensor, which is used to collect the status information of the transmission line. The data processing control module is responsible for grouping the data collected by the data acquisition module, encapsulating and pushing the data to the Beidou short message module for transmission according to the Beidou transmission protocol, and controlling the acquisition module according to the control signal of the control center. Beidou short message module is used to realize the two-way communication between the data processing control module and the control center. The control center has two main tasks: analyze the received Beidou short message data and restore and store the compressed data; The switch of remote control data processing control module and the control data processing control module send the lost data again when the data packet is lost.

\footnotetext{
" Corresponding author: 1574604541@qq.om
} 


\section{2 Operating mode of system}

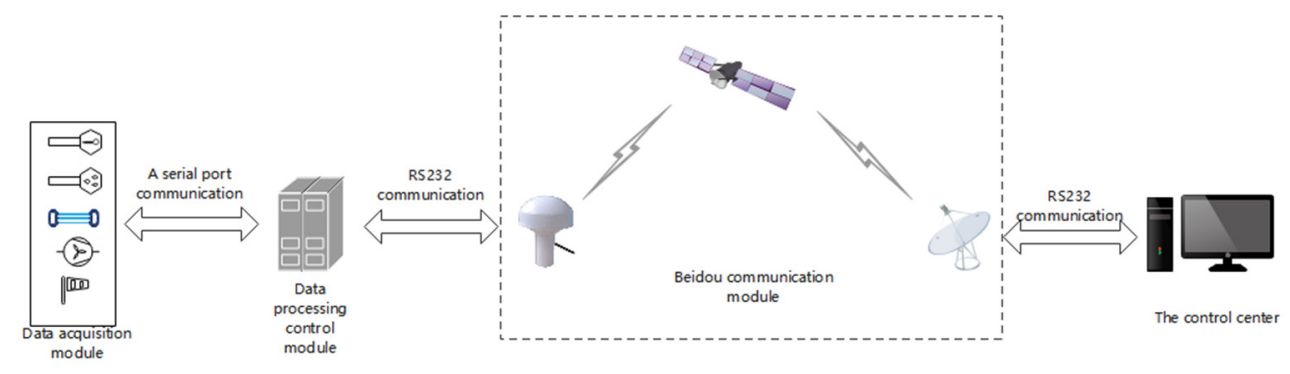

Fig. 1. System structure diagram.

The on-line monitoring system of transmission line based on Beidou short message communication designed in this paper supports two working modes, which aims to meet the requirements of flexible, efficient, stable and reliable monitoring system. The two working modes are automatic acquisition mode and controlled acquisition mode.

- Automatic acquisition mode: The data processing control module controls the acquisition frequency of the data collector module according to the designed program, and automatically packs the transmission line state data through the serial port and transmits it to the Beidou communication module to the control center. Finally, the data is stored and processed after decoding by the control center.
- Controlled acquisition mode: The control center can send instructions to the data processing control module to control the collection frequency according to the actual demand, or when the automatic data collection fails or the data packet is lost, the control center can also send instructions to the data processing control module again.

\section{System hardware design}

\section{1. Hardware design of data processing control module}

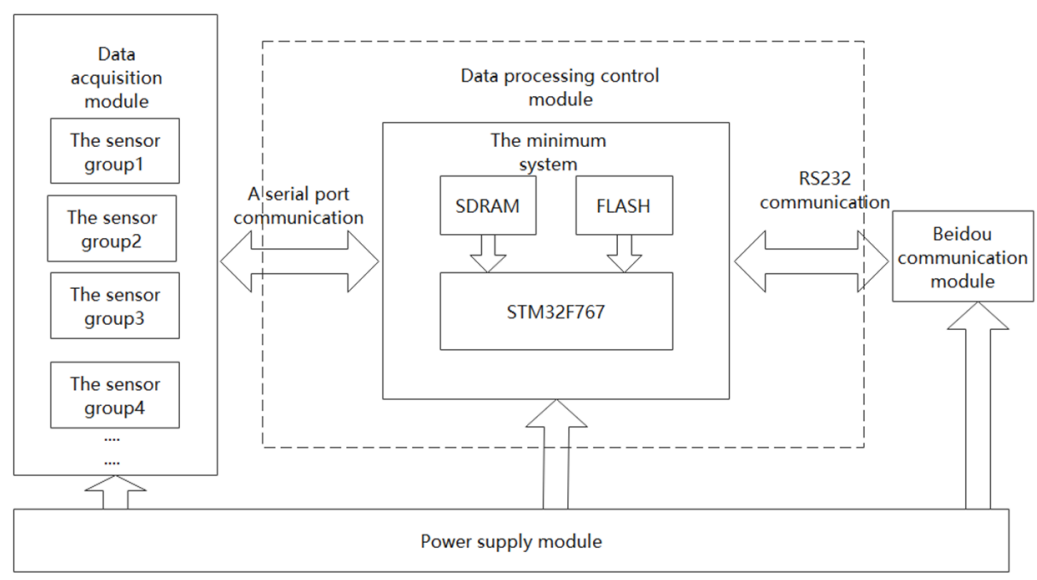

Fig. 2. Hardware structure diagram.

The data processing control module is mainly responsible for coding the data collected by the data acquisition module. And control the acquisition frequency of the acquisition module according to the command of the control center. Its hardware structure diagram is shown in Fig 2. The minimum system is composed of STM32F767 embedded chip as the core. The main frequency of the chip can reach $216 \mathrm{MHz}$, with 512KB SRAM, 1024KB Flash and 12-bit ADC with 3 units and 24 channels, which can meet the requirements of large amount of data and rich data types. Because the data acquisition module may upload the data collected by 8 groups of more than a dozen sensors to the data processing control module at one time, with a large amount of data, and at the same time, the data transmission rate of Beidou short message communication is low (68 Byte/min), so the electricity data need to be stored in the expanded FLASH memory first. Then the
SCM reads the data from the FLASH memory for processing and transmission. In addition, due to the instability of the Beidou communication link, the phenomenon of packet loss may occur in data transmission. Therefore, the storage of electricity data in the FLASH memory can support the retransmission of packet loss data and the backup of data at the sending end, so as to improve the reliability of data transmission. So the chip also expanded SDRAM: W9825G6KH, 32M bytes and NAND FLASH: MT29F4G08, 512M bytes.

\section{2. Hardware design of Beidou communication module}

The Beidou communication module adopts the $\mathrm{C} 230 \mathrm{C}$ Beidou digital transmission user computer, which integrates Beidou multi-frequency antenna, RF, baseband 
and master control function units inside, and can realize RDSS positioning, short message communication and RNSS navigation and positioning and other functions. The length of the message which can transmit 68Byte each time is transmitted once every 60 seconds. Its operating voltage is $7 \mathrm{~V} \sim 36 \mathrm{~V}$, and the standby power consumption is no more than $1.2 \mathrm{~W}$. The emission current of the power supply is more than $500 \mathrm{~mA}$ when the power supply is $19 \mathrm{~V}$. The working temperature is $-25 \sim 70^{\circ} \mathrm{C}$, using waterproof design 8-core waterproof connector and Beidou holder. 8core connector is used for data transmission and power supply of one machine. External serial port default is RS232, baud rate is $4800 \sim 115200$ bps, the default baud rate is $19200 \mathrm{bps}$.

\section{3. Power supply module}

$12 \mathrm{~V}$ and $3.3 \mathrm{~V}$ low-voltage direct current are required for system operation. In the environment of outdoor highvoltage transmission lines, the external power supply cannot be directly connected, but the system can only be supplied by battery. Therefore, the design of power supply system needs to be strengthened. In the outdoor environment, solar energy can be converted into electricity through solar panels for battery charging.

\section{System Software Design}

\section{1. Transmission line status data acquisition and coding method}

\begin{tabular}{|c|c|c|c|c|c|c|}
\hline & $\begin{array}{c}\text { Data start } \\
\text { mark }\end{array}$ & $\begin{array}{l}\text { Sensor group } \\
\text { ID number }\end{array}$ & $\begin{array}{c}\text { Group } \\
\text { number }\end{array}$ & Latitude & Longitude & Time \\
\hline \begin{tabular}{|l|} 
Take up \\
byte space
\end{tabular} & 1Byte & 1Byte & 2Byte & 4Byte & 4Byte & 3Byte \\
\hline Data & $0 \times A A$ & 2 & 5 & $28^{\circ} 11^{\prime} 49 " 30 \mathrm{~N}$ & $\begin{array}{c}112^{\circ} 58^{\prime} 42 \prime \prime \\
40 \mathrm{E}\end{array}$ & $12: 24: 50$ \\
\hline \multirow[t]{2}{*}{ Code } & 0xAA & 2 & 5 & $1 \mathrm{c} 11311 \mathrm{e}$ & $70 \quad 3 a 2 a 28$ & 0c 1832 \\
\hline & $\begin{array}{c}\text { Temperat } \\
\text { ure }\end{array}$ & Humidity & Wind Speed & Direction of the Wind & $\begin{array}{c}\text { Atmospheric } \\
\text { Pressure }\end{array}$ & $\begin{array}{c}\text { Precipita } \\
\text { tion }\end{array}$ \\
\hline \begin{tabular}{|l|} 
Take up \\
byte space
\end{tabular} & 2Byte & 1Byte & 2Byte & 2Byte & 2Byte & 1Byte \\
\hline Data & $35.2^{\circ} \mathrm{C}$ & $10 \% \mathrm{RH}$ & $0.4 \mathrm{~m} / \mathrm{s}$ & $\begin{array}{c}\text { The southeast wind is } \\
140 \text { degrees }\end{array}$ & 900hpa & 0 \\
\hline \multirow[t]{2}{*}{ Code } & 160 & $0 \mathrm{a}$ & 4 & $8 \mathrm{c}$ & 384 & 0 \\
\hline & $\begin{array}{c}\text { Light } \\
\text { intensity }\end{array}$ & Visibility & $\begin{array}{l}\text { Ultraviolet } \\
\text { Intensity }\end{array}$ & Dust concentration & $\begin{array}{l}\text { Data end } \\
\text { mark }\end{array}$ & \\
\hline $\begin{array}{l}\text { Take up } \\
\text { byte space }\end{array}$ & 2Byte & 2Byte & 1Byte & 2Byte & 1Byte & \\
\hline Data & 250000 & $2000 \mathrm{~m}$ & 3. $5 \mathrm{~mW} / \mathrm{cm} 2$ & $200 \mathrm{ug} / \mathrm{m}$ & $0 \times 55$ & \\
\hline code & $09 \mathrm{c} 4$ & $07 \mathrm{~d} 0$ & 23 & c8 & $0 \times 55$ & \\
\hline
\end{tabular}

The single message length of the Beidou communication SIM card used in this paper is 68Byte and the communication frequency is $60 \mathrm{~S} /$ time, which has the disadvantages of limited single message length and limited message communication frequency. And the Beidou communication link has certain unreliability, there is no communication receipt. To solve the above problems, this paper proposes a data processing and coding method:

- Floating point data processing. The data collected by the sensors of temperature, wind speed, precipitation and ultraviolet intensity are of high precision and the resolution can reach 10-1, which is floating-point data. Such as storage and transmission by floating point data, accounting for 4Byte storage space. In this paper, the accuracy of the above data types is only 10-1 bits, and the data can be changed into an integer type after being magnified 10 times. Data transmission only takes up 2Byte storage space. The maximum temperature of the atmospheric temperature data is generally not more than $50^{\circ} \mathrm{C}$, so the data space after the atmospheric temperature value exceeds 100 indicates the sub-zero temperature.

- Integer data processing. The data collected by humidity, wind direction, atmospheric pressure, light intensity, ultraviolet, and dust sensors are all integer data storage occupying 2Byte space. The location information includes longitude and latitude. The format of longitude and latitude data obtained from the Beidou positioning terminal is: range (east longitude or west longitude, north latitude or south latitude, 1 Byte), degree (1 Byte), minute (1 Byte), second (1 Byte) and small second (1 Byte), a total of 5 bytes. The application in this paper is designed for China. Its longitude has been determined to be east 
longitude and latitude to be north latitude, so longitude and latitude occupy 4Byte space respectively. The time information includes hours, minutes and seconds, occupying a total of 3Byte space.

- Data group number and sensor group ID number. In view of the uncertainty of Beidou communication link, packet loss and out-of-order phenomenon will occur. In this paper, the data collected by the same sensor at the same time is divided into a group and the data group number is added to each group of data. When the phenomenon of data packet loss or out-of-order occurs, the corresponding data group can be accurately located, and the request of sending the lost or out-of-order data group again can be sent to the data processing control module. The purpose of designing the ID number of the sensor group is to make one Beidou communication module connect with multiple data acquisition modules, which can effectively improve the efficiency of the Beidou communication module and increase the monitoring range of the monitoring system.

Through the above data processing and encoding methods, the improved data group encoding method is shown in Table 2. The message space occupied by each group of data is 34Byte, so two data groups can be put into each message communication, which can effectively alleviate the problem of limited Beidou communication frequency

\section{2. Software process}

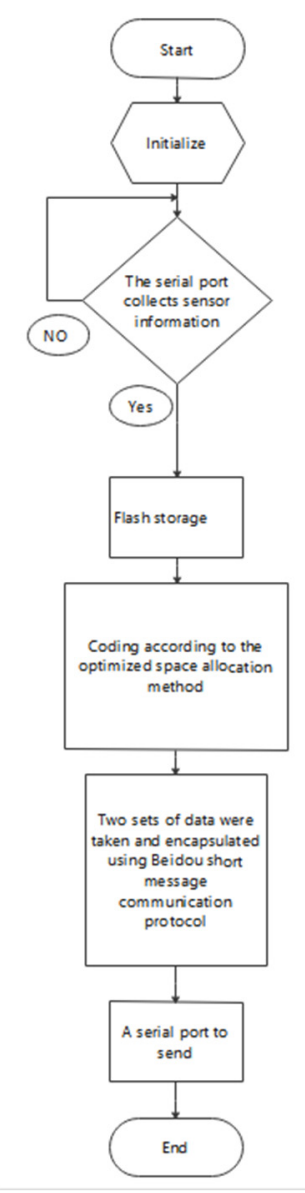

Fig. 3. Sender flow chart.

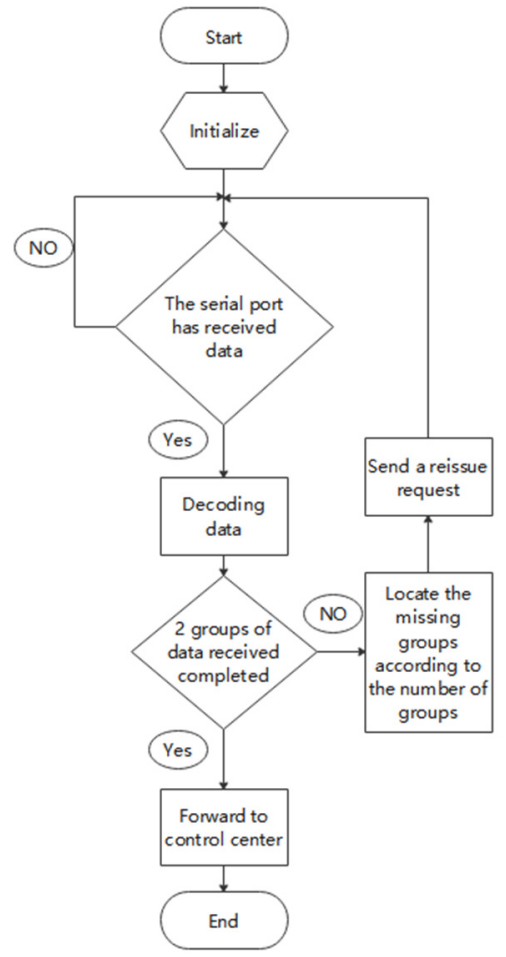

Fig. 4. Receiver flow chart.

Data acquisition module and data processing control module software flow. The data processing control module interacts with the data acquisition module through the serial port, and communicates with the Beidou communication module (sending terminal) through RS232. When the data acquisition module transmits the acquired transmission line status information to the data processing control module through the serial port, the data will be stored in FLASH in the way of interruption and assigned with group number. The main program performs the following operations: The transmission line state information is read from the flash memory and encoded to form a data group according to the encoding method in Table 1. The two groups of data encoded are encapsulated according to the Beidou message format in Table 3-2, so as to realize the transmission of transmission line state information in the Beidou communication link.

Control center module software flow. The Beidou communication module (receiver) is connected with the control center through RS232 serial port. When the Beidou communication module (receiver) receives the short message signal sent out, the control center first parses the short message frame format into the transmission line state data set, and then reads out the state information according to the encoding method of the data set and stores it in the memory of the control center. This paper beidou/time transmission frequency set to 65 seconds, if in a foreseeable time beidou communication failed to receive the beidou short message signals or to receive the out-of-order and noise problems, according to the data set number to locate the missing or out-of-order data set and then request in beidou short message communication front-end to resend the missing child bag, pack up in operation; If the packet patch is not successful, repeat the packet patch operation for $\mathrm{k}$ times at most; If it 
is still unsuccessful, the current transmission line state information collection task is abandoned and the next transmission line state information collection task is performed. If the packet operation can be completed, the complete status data will be pushed to the control center for storage.

\section{Experimental testing}

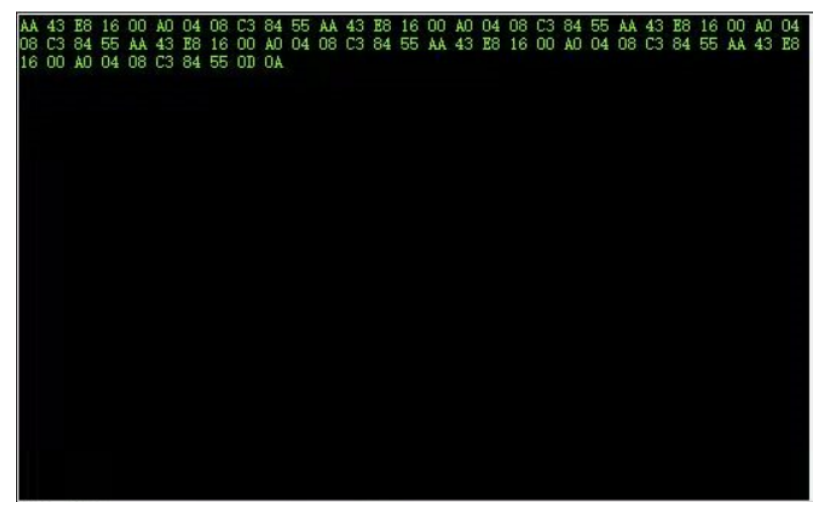

Fig. 5. Diagram of experimental results.

First, set the parameters of the control center. After the correct serial port number and baud rate are configured in the test software of the control center, the serial port information is read. Then start the data acquisition module and data processing control module simultaneously. The information transmitted by the Beidou receiver through the serial port is as shown in Table 2. The information read by the Beidou communication receiver is $0 \mathrm{xAA}$, which is the data starting mark. The following two-digit hexadecimal data is the sensor ID number, which is the second sensor group. The next four hexadecimal numbers represent the fifth group of data. In order to read the data, the information is latitude $28^{\circ} 11^{\prime} 49^{\prime \prime} 30 \mathrm{~N}$, longitude $112^{\circ} 58$ '42 " 40E, time 12: 24 minutes 50 seconds, temperature $35.2^{\circ} \mathrm{C}$, humidity $10 \% \mathrm{RH}$, wind speed 0 . $4 \mathrm{~m} / \mathrm{s}$, wind direction 140 degrees southeast, atmospheric pressure $900 \mathrm{hPa}$, precipitation 0 , light intensity of 250000Lux, visibility $2000 \mathrm{~m}$, UV 3. $5 \mathrm{~mW} / \mathrm{cm} 2$, dust $200 \mathrm{ug} / \mathrm{m}$. The results are consistent with the field manual measurement results, which proves the effectiveness of the system.

\section{Concluding remarks}

This paper studies the problem of difficult data transmission of transmission line online monitoring in remote mountainous areas without wireless mobile network coverage, designs a transmission line online monitoring system based on Beidou short message communication, and focuses on a data coding method and monitoring and transmission equipment. In the data acquisition side, the equipment can monitor the transmission line state information through sensors and encapsulate and transmit the data according to the Beidou communication protocol and designed coding mode. In the receiving side, the Beidou short message communication information is received, and the original data is analyzed and recovered. Encoding the data in a fixed order and in a hexadecimal way can effectively compress the data while ensuring the accuracy of the data, which effectively solves the problem of small data transmission in a single time of Beidou short message communication. Each group of data is designed with a serial number. When the data transmission fails, it can be transmitted again through the serial number, which improves the success rate of data transmission and effectively solves the problem of unstable Beidou transmission. Experiments show that the system developed in this paper has high transmission efficiency and reliability, which can effectively solve the problem of online monitoring of transmission lines in remote mountainous areas without mobile network.

\section{References}

1. GUO Jinghong, ZHANG Hao, LIU Yaxin, LIU Hongbin, WANG Ping, Study on the Data Transmission Technology of Line Condition Monitoring System of Smart Transmission Grid[J], Proceedings of the CSEE, 2011, Vol. 31 (Supplement): 45-49

2. Liu Lirong, Wang Yudong, Xiao Zhihong, Yan Peili, Liu Ying, Xin Peizhe. Research on Communication Transmission Mode of Transmission Line On-line Monitoring System [J]. Power System Communication, 2011, 32(04): 20-25

3. Du Peng, Yan Liang, Gao Baocheng, Wang Xuetao, Li Dantong, Mei Zheng. Wide Area Data Acquisition Scheme Based on Power Dispatching Data Network [J]. Automation of Electric Power Systems, 2019, 43(13): 156-161

4. LIU Xiaoli, BI Liang, HE Xi, et al. Design of communicationsystem with beidou short message for wide area power grid [C]// China Satellite Navigation Conference. Changsha, China: [s. n.], 2016.

5. LIU Jianan, YANG Ronghua, ZHOU Ke, et al. Study on power metering terminal system based on Beidou short message [J]. Guizhou Electric Power Technology, 2016, 19 (2): 6-9.

6. GONG Zhenyu. An engineering project of the compass com-munication[D]. Chengdu: University of Electronic Science and Tech-nology of China, 2015.

7. Zhou Wenting, Wang Tao, Yuan Mingfeng, Wang Lifu, Chen Yuqing, Xia Na. Development of electricity information acquisition system based on Beidou short message communication [J]. Electric Power Automation Equipment, 2017, 37(12): 211-217.

8. Chen Haisheng, Guo Xiaoyun, Wang Feng, Lu Huasheng. Journal of the Chinese Society of Agricultural Engineering, 2015, 31(22): 155-160. 